\title{
Effect of ageing on cervical or vaginal cancer in Swedish women previously treated for cervical intraepithelial neoplasia grade 3: population based cohort study of long term incidence and mortality
}

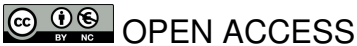

\author{
Björn Strander consultant ${ }^{1}$, Jonas Hällgren biostatistician ${ }^{2}$, Pär Sparén professor ${ }^{2}$ \\ 1Department of Obstetrics and Gynaecology, Institute of Clinical Science, Sahlgrenska Academy, University of Gothenburg, Göteborg, Sweden; \\ ${ }^{2}$ Department of Medical Epidemiology and Biostatistics, Karolinska Institute, Stockholm, Sweden
}

\begin{abstract}
Objective To determine factors influencing long term risks for acquiring or dying from invasive cervical or vaginal cancer in women previously treated for cervical intraepithelial neoplasia grade 3 (CIN3).

Design Population based cohort study conducted in 1958-2008, followed up until 2009 in the Swedish Cancer Registry and Swedish Cause of Death Register, linked to the Swedish Population Register. Standardised incidence and mortality ratios were calculated for the risk of acquiring or dying from vaginal or cervical cancer, with the general female population in Sweden as reference. Relative risks in multivariable regression models were also calculated, adjusting for follow-up duration, treatment period, and age at CIN3 treatment or attained age.

Setting Entire female population of Sweden.
\end{abstract}

Participants 150883 women in Sweden diagnosed and treated with CIN3 and followed up for invasive cervical or vaginal cancer, and related mortality. The cohort comprised 3148222 woman years.

Main outcome measures Standardised incidence and mortality ratios, stratified by period for treatment. Relative standardised incidence ratios and standardised mortality ratios for age at acquiring or dying from cervical or vaginal cancer (attained age), adjusted for preset variables.

Results Women previously diagnosed with CIN3 had an increased risk of dying from invasive cervical or vaginal cancer, compared with the general female population (standardised mortality ratio $2.35,95 \%$ confidence interval 2.11 to 2.61). After age 60 years, these women had an accelerated increased risk of acquiring invasive cancer; a similar steep increase in mortality risk was seen after age 70 . Regression analyses indicated that the increase in risk over time is highly attributable to ageing.

Conclusions Women previously treated for CIN3 are at increased risk of developing and dying from cervical or vaginal cancer, compared with the general female population. The risk accelerates above age 60 years, suggesting a need for lifelong surveillance of these women.

\section{Introduction}

Cytology screening to prevent cervical cancer is a medical success story. Although the sensitivity of a single smear is limited, ${ }^{1}$ repeated examinations of women during the long preinvasive phase of the disease have proved effective in reducing morbidity and mortality. ${ }^{2}$ A recent Swedish study showed non-participation to be the major risk factor related to screening programmes for contracting cervical cancer, particularly in women with advanced cases with high mortality. ${ }^{3}$ The overwhelming majority of women will be effectively protected by participating in the offered screening programme. Although the risk of cervical cancer is substantially reduced, ${ }^{4}$ it is not eliminated when precursor lesions are detected and treated and when women presumably participate in follow-up programmes. We previously reported a 2.5 -fold increased risk of cervical and vaginal cancer among women with a previous diagnosis of cervical intraepithelial neoplasia grade 3 (CIN3), ${ }^{5}$ compared with the general female population. The risk was higher for women aged over 50 years at treatment for CIN3 and for those treated more recently, and persisted for more than 25 years after initial treatment. These findings are in accordance with several smaller studies. ${ }^{6-9}$

Opportunistic screening started in Sweden in the early 1960s, and organised programmes based on national recommendations were introduced in county after county in the late 1960s, with complete national coverage attained in 1975. Initially, women aged 30-50 years were screened; the age limits were extended to 23-60 years in 1985. Treatment for CIN has followed 
international trends (1950s, hysterectomy; 1960-70s, cold knife conisation, inpatient care; 1980s, outpatient cryotherapy or laser conisation and vaporisation; 1990 to present, large loop excision of the transformational zone (LLETZ)). Conducting annual smears for five years after treatment of CIN was the original recommended follow-up. This recommendation was changed in 2009 to 25 years of follow-up after treatment of CIN2-3, as a selective extension of the screening programme. ${ }^{10}$

A literature search of PubMed (in October 2012) revealed only four published papers investigating mortality after treatment for CIN3. All studies were conducted in Finland with inconclusive or conflicting results. Hakama and colleagues found increased overall mortality among women with a diagnosis of CIN3 or carcinoma in situ, but did not report specific data for mortality from cervical or vaginal cancer. ${ }^{11}$ In a small cohort of women treated for CIN3, Kalliala and colleagues found three deaths caused by cervical cancer and three caused by vaginal cancer, but no external comparison was made. ${ }^{12}$ Another study found that women treated for CIN had an overall excess mortality of $17 \%$ and a standard mortality ratio for cervical cancer as high as 7.69 (95\% confidence interval 4.23 to 11.15$).{ }^{13}$ However, a recent study found no significant differences in the risk of death from cervical cancer among women treated for all grades of CIN $(n=7104)$ or for CIN3 $(\mathrm{n}=1175){ }^{14}$

No previous study has investigated how ageing affects the risk of invasive cervical cancer or mortality from cervical cancer after early diagnosis and treatment of CIN. With extensive data from high quality Swedish registers, our aim was to investigate the risk of death from cervical or vaginal cancer among women diagnosed and treated for CIN3. We focused on exploring how attained age (that is, the actual age of a person during follow-up) affected the risk of invasive cancer and cause specific mortality.

\section{Methods}

We retrieved all histopathology reports of cervical carcinoma in situ and severe cervical dysplasia bordering on carcinoma in situ during the period 1958-2008 from the national Swedish Cancer Registry. These diagnoses are equivalent to CIN3, and it is compulsory to report them to the registry. The registry also includes dates of death and emigration through linkages to the national Swedish Cause of Death Register and the national Swedish Population Register, respectively. These registers have proved to be of very high quality. ${ }^{15}$ Data entered into the Swedish Cancer Registry are double checked by concurrent reports from both clinicians and pathology departments.

To comprehensively identify all cases with cervical cancer as the cause of death, we included cases with unspecified cancer in the uterus. We thus included codes from ICD-10 (international classification of diseases, 10th revision) for cervical cancer (C530, C531, C538, C539), vaginal cancer (C52), and uterine cancer unspecified (C55). Furthermore, we only included women previously registered as cervical cancer cases in the Cancer Registry. ${ }^{16}$ All women with diagnosed CIN3 were considered to be treated, because CIN3 verified by biopsy is always treated in Swedish practice. Indeed, in an audit of the Swedish screening programme, ${ }^{17}$ there were no cases of untreated CIN3 found among the 1230 women diagnosed with cervical cancer in 1999-2002. We used the patients' unique personal registration numbers to link their details to the Cancer Registry. In the cohort of 150883 women with CIN3, 1089 had a diagnosis of invasive cervical cancer and 147 women had a diagnosis of vaginal cancer, of whom 302 and 53, respectively, had died of the disease. In this study, we used a composite endpoint of cervical or vaginal cancer, both for mortality and incidence. This was because both cancers share human papillomavirus (HPV) infection as a common risk factor, and because a cancer in the vaginal vault developing after (possibly) incompletely treated CIN3 in a woman with a hysterectomy will be classified as vaginal cancer.

For women with an initial diagnosis of CIN3, we calculated person time at risk, the number of expected cervical or vaginal cancers, and mortality due to cervical or vaginal cancer according to the annual incidence, as well as mortality rates, in five year age groups in the general female population. Using the number of observed and expected cases and deaths, we calculated standardised incidence ratios and standardised mortality ratios with $95 \%$ confidence intervals. To account for prevalent cancers, often detected at follow-up analysis in the pathology department or at immediate clinical follow-up, we excluded the first year of follow-up from the analyses.

Applying multivariable Poisson regression models, we investigated the excess relative risk of incidence and mortality of cervical or vaginal cancer (that is, the ratio of standardised incidence ratios and the ratio of standardised mortality ratios, respectively) for women diagnosed with CIN3, respectively. We assumed that the observed number of cases and deaths from cervical and vaginal cancer followed a Poisson distribution, and we weighted the observed cases and deaths by the log of the number of expected cases and deaths, respectively. To test for linear trends, we assigned ordinal scores to the factor levels and modelled the effect as a continuous variable. The first regression model included age at CIN3 diagnosis, number of years of follow-up, and treatment period. The second model included attained age at diagnosis of invasive cervical or vaginal cancer or death from one of these cancers, number of years of follow-up, and treatment period. Owing to linear dependency between age at diagnosis of CIN3, follow-up duration and attained age, we refrained from applying a full model using all parameters. Instead, we reanalysed the second model while stratifying for age at diagnosis of CIN3.

Goodness of fit for the two regression models was estimated by calculating likelihood ratios, comparing each of them with a fictitious saturated model.

In proportional hazard regression models, we calculated hazard ratios for cause specific survival after diagnosis of invasive cervical cancer in 1958-2009 for women with CIN3, and for all other women without previous diagnosis of CIN3 in Sweden. The group without previous diagnosis $(n=29996)$ was also identified from the national Swedish Cancer Registry.

To validate the regression models of standardised incidence ratios and standardised mortality ratios, we also identified an open cohort of 6692276 Swedish women who were followed up for diagnosed CIN3 or cervical or vaginal cancer from 1 January 1960 to 31 December 2009. A total of 153629 women were diagnosed with CIN3, and 30549 women developed cervical or vaginal cancer during follow-up (web table S1). Excess risk of cervical or vaginal cancer (comparable to standardised incidence ratios) was estimated in multivariable regression models. The web appendix provides further details on the methodology. All analyses were carried out using SAS version 9.3. A two tailed $\mathrm{P}<0.05$ was considered statistically significant. 


\section{Results}

\section{Incidence of cervical and vaginal cancer}

The standardised incidence ratio for women, previously diagnosed with CIN3, to have cervical or vaginal cancer more than one year after the original diagnosis was 2.39 (95\% confidence interval 2.26 to 2.53), based on 3148222 person years of observation and 1236 cases of cancer. The risk of invasive cancer rose with increasing age at diagnosis and treatment of CIN3 and accelerated after the age of 60 years. The risk of invasive cancer also increased the more recently the women had been treated. The standardised incidence ratio for cervical or vaginal cancer was 2.05 (1.83 to 2.30) for women treated during the period 1958-1970, and 4.52 (3.47 to 5.80) for those treated in 2001-08. Women treated for CIN 3 after 30 years of follow-up had a standardised incidence ratio of 1.79 (1.42 to 2.22; 83 observed $v 46$ expected cases; table $1 \Downarrow$ ).

The standardised incidence ratio of invasive cancer of the cervix or vagina also increased with attained age, especially after the age of 60 years (table 1). In absolute terms, the incidence rates after 75 years of age exceeded 100 per 100000 women (fig $1 \Downarrow$ ). Women diagnosed and treated for CIN3 during the past 27 years (1981-2008) seemed to be at higher risk at older ages than women of the same age group treated during the earlier period. In the first multivariable regression model (adjusting for age at CIN3 diagnosis, duration of follow-up, and treatment period), a strong increase in excess relative risk with age at treatment remained - that is, a five times increase in risk for treatment at age 60-69 years, compared with treatment at age 30-39 years. Trend tests for age at treatment, follow-up duration, and treatment period were all highly significant (table $2 \Downarrow$ ).

In a second regression model (adjusting for attained age at diagnosis of or death from cervical or vaginal cancer, duration of follow-up, and treatment period), the excess relative risk of cervical or vaginal cancer increased with increasing attained age, which was accentuated compared with the unadjusted standardised incidence ratio (table $3 \Downarrow$ ). In this model, the excess relative risk associated with follow-up duration decreased strongly, indicating that the increase in risk for cervical or vaginal cancer with follow-up duration is attributable, to a high extent, to ageing in the women previously treated for CIN3. After stratifying for age at treatment ( $<40$ years $v \geq 40$ years), both strata showed increased excess relative risks for invasive vaginal or cervical cancer after attained age 60 years (table $4 \Downarrow$ ).

Likelihood ratio tests showed $P$ values of 0.34 and 0.32 for the first (table 2) and second regression models (table 3),

respectively, versus a saturated model. The increase in risk of cervical or vaginal cancer-related to treatment period from the unadjusted analysis of standardised incidence ratios-persisted in both regression analyses.

The increase in excess risk of cervical or vaginal cancer after diagnosis of CIN 3 was confirmed in the traditional cohort model (web appendix), with a clear and increasing trend over attained age 55-59 years and higher (web table S2). The excess risk varied over time, with no excess in risk during 1960-69, a clear increase to about four times excess risk during 1970-99, and a decrease to around 2.5 times excess risk during 2000-09. We also stratified this cohort model on age at treatment, controlling for calendar period. With increasing age at treatment, there was an increase in excess risk of vaginal or cervical cancer; the risk increased with attained age above 60 years in all age groups except in the youngest groups, in which few women reached age 60 years during follow-up (web table S3). The increase in excess risk over attained age was also confirmed in the restricted cohort model (web table S4).

\section{Mortality from cervical and vaginal cancer}

The standardised mortality ratio for cervical cancer or vaginal cancer for women treated for CIN3 was 2.35 (95\% confidence interval 2.11 to 2.61), based on 3160978 women years and 355 cause specific deaths (table 1 ).

There was a steep increase in mortality with increased age at diagnosis of CIN3. The standardised mortality ratio was also slightly increased for treatment of CIN3 during a more recent period. There was no decreasing trend in standardised mortality ratios with duration of follow-up and the risk was still doubled more than 30 years after treatment, compared with the general population (table 1).

There was an accelerated increase in the standardised mortality ratio for cervical or vaginal cancer with attained age, after 60 years of age. In absolute terms, mortality rates reached 50 per 100000 women at age 72 (fig $2 \Downarrow$ ).

Similar to incidence, mortality also increased with age at treatment, when examined in a multivariable regression model with adjustments for follow-up duration and treatment period (table 2). The relative increase in excess mortality 30 years after treatment for CIN3, observed in the standardised mortality ratio analysis, could now be attributed to the women ageing during follow-up as the effect of follow-up time disappeared (table 3). These data confirm the steep increase in relative risk of excess mortality with old age that was found in the unadjusted analysis of standardised mortality ratios. As opposed to incidence, the apparent relative increase in excess mortality with treatment period did not achieve statistical significance $(\mathrm{P}=0.0646$ for trend) after adjustment for follow-up duration and attained age, nor was this the case in the first model, adjusting for follow-up duration and age at treatment $(\mathrm{P}=0.1563$ for trend $)$.

\section{Prognosis for cervical or vaginal cancer (or both)}

The survival analysis of cause specific mortality from cervical or vaginal cancer at endpoint showed that women diagnosed with cervical cancer and previously treated for CIN3 had a slightly better prognosis than other women diagnosed with cervical cancer and not previously treated for CIN3 (hazard ratio $0.88,95 \%$ confidence interval 0.79 to 0.99 ).

\section{Discussion}

\section{Main findings}

We found that women previously diagnosed with and treated for CIN3 were at substantially increased risk of developing cervical or vaginal cancer when they reached age 60 years. The risk accelerated with further ageing. The data also showed that the risk is additionally increased in women treated for CIN3 late in life.

Mortality generally followed the morbidity pattern, with increased risk if CIN3 was diagnosed and treated late in life. As was the case with incidence, women previously treated for CIN3 had an accelerated increased risk of death from vaginal or cervical cancer when they grew older, compared with women of the same age in the general population.

The background risk for cervical or vaginal cancer was 8.9 per 100000 women (crude incidence 2011) in the Swedish female population at large and 10.2 per 100000 in women aged 70 years according to the Swedish Cancer Registry. However, the 
incidence in the cohort of women diagnosed with CIN3 exceeded 70 per 100000 women at age 70 years (fig 1). The studied cohort consisted of 150000 Swedish women with an accumulated follow-up of more than 3.1 million woman years.

The high absolute risks of acquiring cervical or vaginal cancer and dying of these diseases when women previously treated for CIN3 reach old age are unique findings, with no other published studies on the subject to our knowledge. Finnish researchers have published data for mortality after treatment of CIN, but those studies were partly designed for other outcomes. Kalliala and colleagues ${ }^{14}$ found no increased mortality from cervical cancer among women previously treated for any grade of CIN—or specifically for CIN3 - despite earlier finding, ${ }^{13}$ also in Finland, of excess morbidity. That study was smaller, with 14217 woman years of follow-up in the CIN3 cohort, which was less than $0.5 \%$ of the person years in our study. Despite low power and wide confidence intervals, the reported hazard ratio of 1.5 nonetheless concurred with the results of our study. Jakobsson and colleagues ${ }^{13}$ studied a cohort that was younger (age 15-49 years) and smaller ( $n=25897$, number of person years not stated) than in our study, with all grades of CIN for a shorter time period (1986-2006). They found a high risk ratio (7.69) that was derived from 19 observed cases of deaths from cervical cancer, compared with 2.2 expected cases.

Our results of increasing excess risk of cervical or vaginal cancer with increasing age in women previously diagnosed with CIN3 were confirmed when we applied a traditional cohort model with individual follow-up of all women.

We have previously reported that women treated more recently seem to have an increased risk of acquiring cervical or vaginal cancer, compared with women treated before $1970 .{ }^{5}$ Although these more recent data confirm this observation, this conclusion should be regarded as preliminary because we were not able to confirm this finding in the traditional cohort model. One reason for such development could be that treatment has become more conservative and tissue sparing (LLETZ), an effect of increasing evidence that treatment of precancerous lesions increases the risk of future preterm delivery, ${ }^{18}{ }^{19}$ and it might thus be related to the amount of tissue resected or destroyed.

\section{Strengths and weaknesses}

One weakness of this study was that we have no data on how these treated women were actually followed up. Thus we cannot ascertain whether survivors of cervical or vaginal cancer underwent more intense or protracted cytological follow-up than the women who died. We have not included specific data on hysterectomies, but this is compensated for by the inclusion of both vaginal and cervical cancer as a composite outcome. However, we cannot calculate the degree of protection provided by a hysterectomy after treatment, or as treatment, for CIN3.

Data on cause of death in the Swedish Cause of Death Register are less reliable than incident cancer diagnoses in the Swedish Cancer Registry. ${ }^{20}{ }^{21}$ We took this into account by only including deaths in individuals already registered as having had cervical or vaginal cancer in the Cancer Registry. This conservative approach excluded $23 \%$ of the deaths from cervical or vaginal cancer in the Cause of Death Register.

Comparing the likelihood ratios between the two regression models - with attained age at cancer diagnosis in one model, and age at treatment of CIN3 in the other-provided equally good explanations for the results. Age at treatment has a modifying effect but we nonetheless emphasise the high risk found for women previously treated for CIN3 when they reach old age. We failed to identify a "safe" age for treatment, at which follow-up in old age would be unnecessary. After stratifying the risk of attained age on age at treatment for CIN3, we still saw an increased cancer risk after age 60 years for women who were treated at young ages. This finding was also supported by results in the supplementary cohort study (web appendix). Few women treated when younger than 30 years have reached age 60 , because this age group was not offered screening in Sweden until the mid-1980s.

The long follow-up - more than 45 years - might favour a selection of individuals who are otherwise healthier than average. Such a positive selection bias would presumably lead to an underestimation of the true risk with older age. There is also most certainly an observational bias with more intense, short term surveillance of women treated for CIN3, compared with the general population. As more preinvasive lesions will probably be found, this bias will also lead to an underestimation of the risks of invasive cancer in old age.

The strength of this study was the large amount of data from registers documented to be complete and comprehensive, and the fact that it was based on the entire population of one country. The data emanate from a fairly uniform, publicly funded healthcare system with nationwide organised screening for more than 35 years and with similar regional routines for CIN treatment and follow-up, although routines have changed over time. $^{22}$ The generalisability of the results is high, because there is high concordance in diagnosis and treatment of CIN3 throughout the world. Countries with inferior screening programmes and less systematic follow-up of women treated for CIN3 than is historically the case in Sweden might expect an even worse outcome. ${ }^{23} \mathrm{We}$ were also able to confirm our main results, using a more traditional approach in a cohort study in which close to seven million Swedish women were followed for diagnosis of CIN3 and invasive cervical or vaginal cancer during five decades.

Some studies have shown a low risk of developing cervical cancer after age 60 years if the woman has had several normal smears before that age. ${ }^{24-26}$ This has been the rationale for stopping cervical screening programmes at a defined age-age 60 years in Sweden-disregarding the specific needs of women with a history of precancerous lesions.

We do not know whether the increased risk of contracting and dying from cervical or vaginal cancer was due to incomplete treatment of CIN3 or due to an increased baseline risk for cancer in this group of women. It is likely that environmental risk factors (smoking, sexual habits, HPV exposure) tend to accompany women throughout life to some extent-as do risk related genetic characteristics. These women's immune systems, having already failed to clear and prevent progress of HPV induced lesions once, might be even further impaired in old age. ${ }^{27}$

\section{Meaning of the study}

After treatment for CIN3, women can be reassured that they are well protected from cervical cancer. Only a small minority of those treated will develop cancer and die from the disease. Still, the risk is higher than that in the general female population, particularly as the main risk factor among women with cervical cancer is not having been screened at all. ${ }^{328}$ Women treated for CIN3 have not only been screened and treated, but can also be assumed to have been followed up more closely (at least for a time) than other women of the same age. When these women age, they have an excess risk for developing cervical cancer that exceeds the calculated risk for an unscreened population ${ }^{29}$ and they are easily identifiable. The main implication of this study 
is that women previously treated for CIN3 also need surveillance in old age, perhaps as long as it is practical to visit a physician or a nurse to take a smear. Emphasis should be placed on continued surveillance in old age, rather than on follow-up for a specified number of years after treatment, the strategy suggested, for instance, in the new US guidelines. ${ }^{30}$ Women aged under 30 years when treated may not need lifelong surveillance, but further research is needed on this topic. A small number of women diagnosed and treated for CIN3 after age 60 years have a particularly increased risk of invasive cancer. Although we do not know whether this is due to incomplete treatment, it should be regarded as a clinical challenge, suggesting that these women should be managed by expert colposcopists and be discussed at multidiciplinary clinical conferences.

\section{Unanswered questions and future research}

The best test to use for long term follow-up remains to be investigated. Cytology should not be ruled out, based on these data. Cytological screening has proved effective, also at older ages. ${ }^{31}{ }^{32}$ However, a more sensitive test (such as HPV DNA testing) is probably better, ${ }^{33}{ }^{34}$ although its value for long term follow-up has not been convincing so far. ${ }^{35}{ }^{36}$ Trials of HPV testing at the upper age limit of the screening programme ("exit test") and continued surveillance only of HPV positive women could provide important knowledge. Furthermore, the effect of different screening intervals should be considered, and health economic analyses are needed. Additional research should also investigate the observed - but not confirmed - trend of increased long term risk for women treated more recently.

\section{Conclusion}

The risk of developing and dying from cervical or vaginal cancer among women previously treated for CIN3 is strongly increased after the ages of 60 and 70 years, respectively. Treatment later in life enhances this risk. Women previously treated for CIN3 should be followed up in old age.

Contributors: All authors contributed to study design, acquisition of data, and interpretation of data. $\mathrm{JH}$ had the main responsibility for statistical analysis but all authors contributed. BS and PS wrote the manuscript, and all authors reviewed and commented on drafts and approved the final manuscript and the decision to submit for publication. BS and PS are the guarantors of the study, accept full responsibility for the research, had access to the data and controlled the decision to publish.

Funding: This study was supported by the Halland County Scientific Board and the Swedish Cancer Society. These sources had no role in the design or conduct of the study; collection, management, analysis, and interpretation of the data; or preparation, review, or approval of the manuscript.

Competing interests: All authors have completed the ICMJE uniform disclosure form at www.icmje.org/coi_disclosure.pdf and declare: support from the Halland County Scientific Board and the Swedish Cancer Society for the submitted work; no financial relationships with any organisations that might have an interest in the submitted work in the previous three years; no other relationships or activities that could appear to have influenced the submitted work.

Ethical approval: Data retrieval was approved by the Ethics Committee at the Karolinska Institute (Dnr 02-556, 2011/921-32).

Data sharing: Statistical code and dataset are available from par.sparen@ki.se.

The guarantors affirm that the manuscript is an honest, accurate, and transparent account of the study being reported; that no important aspects of the study have been omitted; and that any discrepancies from the study as planned have been explained.

1 Naucler P, Ryd W, Tornberg S, Strand A, Wadell G, Elfgren K, et al. Efficacy of HPV DNA testing with cytology triage and/or repeat HPV DNA testing in primary cervical cancer screening. J Natl Cancer Inst 2009;101:88-99.

2 Arbyn M, Rebolj M, De Kok IM, Fender M, Becker N, O'Reilly M, et al. The challenges of organising cervical screening programmes in the 15 old member states of the European Union. Eur J Cancer 2009;45:2671-8.

3 Andrae B, Kemetli L, Sparen P, Silfverdal L, Strander B, Ryd W, et al.

Screening-preventable cervical cancer risks: evidence from a nationwide audit in Sweden J Natl Cancer Inst 2008;100:622-9.

4 McCredie MRE, Sharples KJ, Paul C, Baranyai J, Medley G, Jones RW, et al. Natural history of cervical neoplasia and risk of invasive cancer in women with cervical intraepithelial neoplasia 3: a retrospective cohort study. Lancet Oncol 2008;9:425-34.

5 Strander B, Andersson-Ellstrom A, Milsom I, Sparén P. Long term risk of invasive cance after treatment for cervical intraepithelial neoplasia grade 3: population based cohort study. BMJ 2007;335:1077

6 Mitchell H, Medley G, Carlin JB. Risk of subsequent cytological abnormality and cancer among women with a history of cervical intraepithelial neoplasia: a comparative study. Cancer Causes Control 1990;1:143-8.

7 Pettersson F, Malker B. Invasive carcinoma of the uterine cervix following diagnosis and treatment of in situ carcinoma. Record linkage study within a National Cancer Registry. Radiother Oncol 1989;16:115-20.

8 Soutter WP, Sasieni P, Panoskaltsis T. Long-term risk of invasive cervical cancer after treatment of squamous cervical intraepithelial neoplasia. Int J Cancer 2006;118:2048-55

9 Rapiti E, Usel M, Neyroud-Caspar I, Merglen A, Verkooijen HM, Vlastos AT, et al. Omission of excisional therapy is associated with an increased risk of invasive cervical cancer after cervical intraepithelial neoplasia III. Eur J Cancer 2012;48:845-52.

10 Swedish work and reference group for cervical cancer prevention within the Swedish Society of Obstetrics and Gynecology (C-ARG), ed. Cervical cancer prevention—guidelines for management, treatment and follow up of CIN. [Cervixcancerprevention-riktlinjer för utredning, behandling och uppföljning av cervikal intraepitelial neoplasi (CIN).] In Swedish. English summary, 2010.

11 Hakama M, Luostarinen T, Hakulinen T. Survival of in situ carcinoma of cervix uteri: a 50-year follow-up in Finland. Int J Cancer 2004;112:1072-4.

12 Kalliala I, Nieminen P, Dyba T, Pukkala E, Anttila A. Cancer free survival after CIN treatment: comparisons of treatment methods and histology. Gynecol Oncol 2007;105:228-33.

13 Jakobsson M, Gissler M, Paavonen J, Tapper AM. Long-term mortality in women treated for cervical intraepithelial neoplasia. BJOG 2009;116:838-44.

14 Kalliala I, Dyba T, Nieminen P, Hakulinen T, Anttila A. Mortality in a long-term follow-up after treatment of CIN. Int J Cancer 2010;126:224-31.

15 Barlow L, Westergren K, Holmberg L, Tallback M. The completeness of the Swedish Cancer Register: a sample survey for year 1998. Acta Oncol 2009;48:27-33.

16 Mattsson B, Wallgren A. Completeness of the Swedish Cancer Register. Non-notified cancer cases recorded on death certificates in 1978. Acta Radiol Oncol 1984:23:305-13.

17 Silfverdal L, Kemetli L, Sparen P, Andrae B, Strander B, Ryd W, et al. Risk of invasive cervical cancer in relation to clinical investigation and treatment after abnormal cytology: a population-based case-control study. Int J Cancer 2011;129:1450-8.

18 Noehr B, Jensen A, Frederiksen K, Tabor A, Kjaer SK. Loop electrosurgical excision of the cervix and subsequent risk for spontaneous preterm delivery: a population-based study of singleton deliveries during a 9-year period. Am J Obstet Gynecol 2009;201:33.e1-6.

19 Arbyn M, Kyrgiou M, Simoens C, Raifu AO, Koliopoulos G, Martin-Hirsch P, et al. Perinatal mortality and other severe adverse pregnancy outcomes associated with treatment of cervical intraepithelial neoplasia: meta-analysis. BMJ 2008;337:a1284.

20 Mattsson B, Rutqvist LE, Wallgren A. Comparison between diagnoses in the Stockholm Regional Cancer Register and certified underlying causes of death. Acta Radiol Oncol 1985;24:219-26.

21 Fall K, Stromberg F, Rosell J, Andren O, Varenhorst E. Reliability of death certificates in prostate cancer patients. Scand J Urol Nephrol 2008;42:352-7.

22 Strander B. Cervical cancer prevention [thesis]. Gothenburg University, 2008.

23 Ronco G, Sideri MG, Ciatto S. Cervical intraepithelial neoplasia and higher long term risk of cancer. BMJ 2007;335:1053-4

24 Cruickshank ME, Angus V, Kelly M, McPhee S, Kitchener HC. The case for stopping cervical screening at age 50. Br J Obstet Gynaecol 1997;104:586-9.

25 Sasieni P, Adams J, Cuzick J. Benefit of cervical screening at different ages: evidence from the UK audit of screening histories. Br J Cancer 2003;89:88-93.

26 Van Wijngaarden WJ, Duncan ID. Rationale for stopping cervical screening in women over 50. BMJ 1993:306:967-71.

27 DeVeale B, Brummel T, Seroude L. Immunity and aging: the enemy within? Aging Cell 2004;3:195-208

28 Sasieni PD, Cuzick J, Lynch-Farmery E. Estimating the efficacy of screening by auditing smear histories of women with and without cervical cancer. The National Co-ordinating Network for Cervical Screening Working Group. Br J Cancer 1996;73:1001-5.

29 Barken SS, Rebolj M, Andersen ES, Lynge E. Frequency of cervical intraepithelial neoplasia treatment in a well-screened population. Int J Cancer 2011;2011:26248.

30 Practice Bulletin. Screening for cervical cancer. Obstet Gynecol 2012;120:1222-38.

31 Cuzick J, Arbyn M, Sankaranarayanan R, Tsu V, Ronco G, Mayrand MH, et al. Overview of human papillomavirus-based and other novel options for cervical cancer screening in developed and developing countries. Vaccine 2008;26 suppl 10:K29-41.

32 Cuzick J, Beverley E, Ho L, Terry G, Sapper H, Mielzynska I, et al. HPV testing in primary screening of older women. Br J Cancer 1999;81:554-8.

33 Kocken M, Helmerhorst TJ, Berkhof J, Louwers JA, Nobbenhuis MA, Bais AG, et al. Risk of recurrent high-grade cervical intraepithelial neoplasia after successful treatment: a long-term multi-cohort study. Lancet Oncol 12:441-50.

34 Legood R, Smith M, Lew JB, Walker R, Moss S, Kitchener H, et al. Cost effectiveness of human papillomavirus test of cure after treatment for cervical intraepithelial neoplasia in England: economic analysis from NHS Sentinel Sites Study. BMJ 2012;345:e7086.

35 Cruickshank ME, Sharp L, Chambers G, Smart L, Murray G. Persistent infection with human papillomavirus following the successful treatment of high grade cervical intraepithelial neoplasia. BJOG 2002;109:579-81. 


\section{What is already known on this topic}

Women previously treated for cervical intraepithelial neoplasia grade 3 (CIN3) have an increased risk of acquiring cervical or vaginal cancer compared with the general population

This risk persists at least 25 years after treatment for CIN3

There are conflicting results concerning mortality from small studies and the importance of ageing in treated women has not been studied

\section{What this study adds}

Women previously treated for CIN3 have a more than doubled risk of death from cervical or vaginal cancer compared with women in the general population

The risk of treated women contracting or dying from cervical or vaginal cancer increases considerably with older age. Attained age and age at treatment explain the increase in long term risk

These findings might have important implications for management, because women treated for CIN3 apparently need follow-up until old age

36 Strander B, Ryd W, Wallin KL, Warleby B, Zheng B, Milsom I, et al. Does HPV-status 6-12 months after treatment of high grade dysplasia in the uterine cervix predict long term recurrence? Eur J Cancer 2007;43:1849-55.

Accepted: 29 November 2013

\section{Cite this as: BMJ 2014;348:f736}

This is an Open Access article distributed in accordance with the Creative Commons Attribution Non Commercial (CC BY-NC 3.0) license, which permits others to distribute, remix, adapt, build upon this work non-commercially, and license their derivative works on different terms, provided the original work is properly cited and the use is non-commercial. See: http://creativecommons.org/licenses/by-nc/3.0/. 


\section{Tables} Table 1 | Standardised incidence ratios and standardised mortality ratios for cervical or vaginal cancer among women with previous CIN3
diagnosis

\begin{tabular}{|c|c|c|c|c|c|c|c|c|}
\hline \multirow[b]{2}{*}{ Parameter } & \multicolumn{4}{|c|}{ Incidence } & \multicolumn{4}{|c|}{ Mortality } \\
\hline & $\begin{array}{l}\text { Observed } \\
\text { no of cases }\end{array}$ & $\begin{array}{l}\text { Expected } \\
\text { no of } \\
\text { cases }\end{array}$ & $\begin{array}{l}\text { Standardised incidence } \\
\text { ratios }(95 \% \mathrm{Cl})\end{array}$ & $\begin{array}{l}\text { Person time at } \\
\text { risk (years) }\end{array}$ & $\begin{array}{l}\text { Observed } \\
\text { no of } \\
\text { cases }\end{array}$ & $\begin{array}{l}\text { Expected } \\
\text { no of } \\
\text { cases }\end{array}$ & $\begin{array}{l}\text { Standardised mortality } \\
\text { ratios }(95 \% \mathrm{Cl})\end{array}$ & $\begin{array}{l}\text { Person time at } \\
\text { risk (years) }\end{array}$ \\
\hline Whole cohort & 1236 & 517 & 2.39 (2.26 to 2.53$)$ & 3148222 & 355 & 151 & 2.35 (2.11 to 2.61$)$ & 3160978 \\
\hline \multicolumn{9}{|c|}{ Age at treatment of CIN3 (years) } \\
\hline$<20$ & 5 & 5 & $1.09(0.36$ to 2.55$)$ & 39114 & 0 & 1 & $0(0$ to 4.50$)$ & 39185 \\
\hline $20-29$ & 216 & 158 & 1.37 (1.19 to 1.57$)$ & 1083345 & 42 & 28 & 1.50 (1.08 to 2.03$)$ & 1086048 \\
\hline 30-39 & 403 & 199 & 2.03 (1.83 to 2.24$)$ & 1227538 & 82 & 54 & $1.52(1.21$ to 1.89$)$ & 1232607 \\
\hline $40-49$ & 295 & 113 & 2.62 (2.33 to 2.94$)$ & 597470 & 108 & 46 & 2.33 (1.92 to 2.82$)$ & 600230 \\
\hline $50-59$ & 178 & 32 & 5.65 (4.85 to 6.54$)$ & 150808 & 65 & 16 & 4.12 (3.18 to 5.25$)$ & 152307 \\
\hline $60-69$ & 93 & 9 & 10.58 (8.54 to 12.96$)$ & 38603 & 38 & 5 & 7.60 (5.38 to 10.43$)$ & 39099 \\
\hline $70-79$ & 39 & 2 & 16.54 (11.76 to 22.62$)$ & 10175 & 17 & 2 & 11.25 (6.56 to 18.02$)$ & 10322 \\
\hline$\geq 80$ & 7 & 0 & 28.67 (11.53 to 59.08 ) & 1169 & 3 & 0 & 17.79 (3.67 to 52.00$)$ & 1180 \\
\hline \multicolumn{9}{|c|}{ Treatment period (calendar year) } \\
\hline $1958-70$ & 308 & 150 & 2.05 (1.83 to 2.30$)$ & 739483 & 128 & 59 & 2.18 (1.82 to 2.60$)$ & 743065 \\
\hline $1971-80$ & 388 & 181 & 2.14 (1.93 to 2.36$)$ & 1139381 & 120 & 53 & 2.25 (1.86 to 2.68$)$ & 1144118 \\
\hline $1981-90$ & 322 & 119 & 2.71 (2.42 to 3.02 ) & 799922 & 68 & 27 & 2.50 (1.94 to 3.17$)$ & 803280 \\
\hline $1991-2000$ & 156 & 53 & 2.96 (2.52 to 3.47$)$ & 369239 & 34 & 10 & $3.40(2.36$ to 4.76$)$ & 370183 \\
\hline 2001-08 & 62 & 14 & 4.52 (3.47 to 5.80$)$ & 100196 & 5 & 2 & 2.64 (0.86 to 6.16$)$ & 100333 \\
\hline \multicolumn{9}{|c|}{ Follow-up duration (years) } \\
\hline 1 & 96 & 25 & 3.85 (3.12 to 4.70$)$ & 148875 & 2 & 5 & 0.39 (0.05 to 1.41$)$ & 148922 \\
\hline $2-4$ & 222 & 73 & 3.05 (2.66 to 3.48 ) & 422809 & 34 & 16 & 2.19 (1.51 to 3.05$)$ & 423350 \\
\hline $5-9$ & 310 & 110 & 2.82 (2.51 to 3.15 ) & 631386 & 70 & 26 & 2.74 (2.13 to 2.13 ) & 633130 \\
\hline $10-14$ & 218 & 92 & 2.37 (2.07 to 2.71 ) & 542459 & 64 & 24 & 2.65 (2.04 to 3.39 ) & 544771 \\
\hline $15-19$ & 141 & 73 & 1.92 (1.62 to 2.26 ) & 461303 & 64 & 22 & 2.90 (2.23 to 3.70$)$ & 463774 \\
\hline $20-24$ & 100 & 57 & 1.77 (1.44 to 2.15$)$ & 373008 & 30 & 19 & 1.54 (1.04 to 2.20$)$ & 375150 \\
\hline $25-29$ & 66 & 41 & $1.62(1.26$ to 2.07$)$ & 273961 & 36 & 17 & 2.18 (1.53 to 3.02$)$ & 275615 \\
\hline$\geq 30$ & 83 & 46 & 1.79 (1.42 to 2.22$)$ & 294421 & 55 & 23 & 2.42 (1.82 to 3.15$)$ & 296267 \\
\hline \multicolumn{9}{|c|}{ Attained age at diagnosis of cervical or vaginal cancer (years) } \\
\hline$<20$ & 0 & 0 & Not applicable & 782 & 0 & 0 & Not applicable & 782 \\
\hline $20-29$ & 33 & 12 & 2.71 (1.87 to 3.81$)$ & 155757 & 4 & 1 & $4.00(1.09$ to 10.25$)$ & 155782 \\
\hline 30-39 & 219 & 114 & $1.93(1.68$ to 2.20$)$ & 659989 & 15 & 15 & $0.99(0.55$ to 1.63$)$ & 660905 \\
\hline $40-49$ & 290 & 155 & $1.87(1.66$ to 2.10$)$ & 877996 & 49 & 34 & $1.46(1.08$ to 1.93$)$ & 880963 \\
\hline $50-59$ & 235 & 113 & 2.08 (1.82 to 2.36$)$ & 762490 & 76 & 40 & 1.92 (1.51 to 2.41$)$ & 765887 \\
\hline $60-69$ & 222 & 72 & 3.08 (2.68 to 3.51 ) & 446357 & 71 & 32 & 2.19 (1.71 to 2.76$)$ & 449048 \\
\hline $70-79$ & 165 & 39 & 4.28 (3.65 to 4.99$)$ & 188538 & 94 & 21 & 4.44 (3.59 to 5.43 ) & 190421 \\
\hline$\geq 80$ & 72 & 12 & 5.96 (4.66 to 7.51$)$ & 56312 & 46 & 8 & 5.57 (4.08 to 7.42$)$ & 57190 \\
\hline
\end{tabular}




\begin{tabular}{|c|c|c|c|c|}
\hline \multirow[b]{2}{*}{ Parameter } & \multicolumn{2}{|c|}{ Incidence } & \multicolumn{2}{|c|}{ Mortality } \\
\hline & No of cases & Excess relative risk $(95 \% \mathrm{Cl})$ & No of cases & Excess relative risk $(95 \% \mathrm{Cl})$ \\
\hline \multicolumn{5}{|c|}{ Age at treatment of CIN3 (years) } \\
\hline$\leq 29$ & 221 & 0.68 (0.58 to 0.80$)$ & 42 & $0.93(0.64$ to 1.35$)$ \\
\hline 30-39 (reference) & 403 & 1.00 & 82 & 1.00 \\
\hline $40-49$ & 295 & 1.37 (1.18 to 1.59$)$ & 108 & 1.58 (1.18 to 2.10$)$ \\
\hline $50-59$ & 178 & 2.88 (2.41 to 3.44$)$ & 65 & 2.85 (2.05 to 3.95$)$ \\
\hline $60-69$ & 93 & 4.95 (3.94 to 6.21$)$ & 38 & 5.31 (3.58 to 7.87 ) \\
\hline $70-79$ & 39 & 7.02 (5.04 to 9.79$)$ & 17 & 8.15 (4.73 to 14.03$)$ \\
\hline$\geq 80$ & 7 & 11.35 (5.36 to 24.04$)$ & 3 & 14.49 (4.50 to 46.73$)$ \\
\hline \multicolumn{5}{|c|}{ Follow-up duration (years) } \\
\hline 1 & 96 & $1.20(0.95$ to 1.53$)$ & 2 & $0.17(0.04$ to 0.71$)$ \\
\hline 2-4 (reference) & 222 & 1.00 & 34 & 1.00 \\
\hline $5-9$ & 310 & $1.00(0.84$ to 1.19$)$ & 70 & 1.35 (0.89 to 2.04$)$ \\
\hline $10-14$ & 218 & $0.90(0.74$ to 1.09$)$ & 64 & 1.44 (0.94 to 2.21$)$ \\
\hline $15-19$ & 141 & 0.75 (0.61 to 0.94$)$ & 64 & $1.73(1.13$ to 2.67$)$ \\
\hline $20-24$ & 100 & 0.72 (0.57 to 0.92$)$ & 30 & 1.00 (0.60 to 1.65$)$ \\
\hline $25-29$ & 66 & 0.71 (0.53 to 0.94$)$ & 36 & $1.52(0.93$ to 2.48$)$ \\
\hline$\geq 30$ & 83 & $0.85(0.65$ to 1.11$)$ & 55 & 1.85 (1.17 to 2.92$)$ \\
\hline \multicolumn{5}{|c|}{ Treatment period (calendar year) } \\
\hline $1958-70$ (reference) & 308 & 1.00 & 128 & 1.00 \\
\hline $1971-80$ & 388 & $1.18(1.01$ to 1.38$)$ & 120 & $1.07(0.83$ to 1.38$)$ \\
\hline $1981-90$ & 322 & $1.44(1.22$ to 1.70$)$ & 68 & $1.17(0.85$ to 1.60$)$ \\
\hline $1991-2000$ & 156 & 1.26 (1.03 to 1.55$)$ & 34 & 1.29 (0.86 to 1.95$)$ \\
\hline 2001-08 & 62 & 1.93 (1.45 to 2.57$)$ & 5 & $1.39(0.55$ to 3.51$)$ \\
\hline \multicolumn{5}{|l|}{$\mathrm{P}$ for trend ${ }^{*}$} \\
\hline Age at treatment & $<0.001$ & - & $<0.001$ & - \\
\hline Follow-up duration & $<0.001$ & - & 0.0022 & - \\
\hline Treatment period & $<0.001$ & - & 0.1563 & - \\
\hline
\end{tabular}


Table 3| Excess relative risk of developing or dying from invasive cervical or vaginal cancer (second regression model), among women with previous CIN3 diagnosis*

\begin{tabular}{|c|c|c|c|c|}
\hline \multirow[b]{2}{*}{ Parameter } & \multicolumn{2}{|c|}{ Incidence } & \multicolumn{2}{|c|}{ Mortality } \\
\hline & No of cases & Excess relative risk $(95 \% \mathrm{Cl})$ & No of cases & Excess relative risk $(95 \% \mathrm{Cl})$ \\
\hline \multicolumn{5}{|l|}{ Attained age } \\
\hline$\leq 29$ & 33 & $1.17(0.81$ to 1.70$)$ & 4 & $4.76(1.57$ to 14.47$)$ \\
\hline 30-39 (reference) & 219 & 1.00 & 15 & 1.00 \\
\hline $40-49$ & 290 & $1.28(1.07$ to 1.53$)$ & 49 & 1.61 (0.90 to 2.88$)$ \\
\hline $50-59$ & 235 & 1.96 (1.62 to 2.38$)$ & 76 & 2.49 (1.41 to 4.39$)$ \\
\hline $60-69$ & 222 & 3.93 (3.21 to 4.82 ) & 71 & $3.48(1.95$ to 6.21$)$ \\
\hline $70-79$ & 165 & 6.85 (5.48 to 8.56$)$ & 94 & $8.42(4.75$ to 14.95$)$ \\
\hline$\geq 80$ & 72 & 10.22 (7.68 to 13.61$)$ & 46 & 11.06 (5.99 to 20.45 ) \\
\hline \multicolumn{5}{|c|}{ Follow-up duration (years) } \\
\hline 1 & 96 & $1.29(1.01$ to 1.64$)$ & 2 & $0.18(0.04$ to 0.75$)$ \\
\hline 2-4 (reference) & 222 & 1.00 & 34 & 1.00 \\
\hline $5-9$ & 310 & 0.87 (0.73 to 1.04$)$ & 70 & 1.18 (0.78 to 1.79$)$ \\
\hline $10-14$ & 218 & 0.64 (0.52 to 0.77 ) & 64 & $1.02(0.66$ to 1.57$)$ \\
\hline $15-19$ & 141 & 0.42 (0.33 to 0.52$)$ & 64 & $0.97(0.62$ to 1.51$)$ \\
\hline $20-24$ & 100 & $0.31(0.24$ to 0.40$)$ & 30 & $0.43(0.25$ to 0.72$)$ \\
\hline $25-29$ & 66 & $0.22(0.17$ to 0.30$)$ & 36 & 0.49 (0.29 to 0.82$)$ \\
\hline$\geq 30$ & 83 & $0.18(0.13$ to 0.24$)$ & 55 & $0.40(0.24$ to 0.65$)$ \\
\hline \multicolumn{5}{|c|}{ Treatment period (calendar year) } \\
\hline 1958-70 (reference) & 308 & 1.00 & 128 & 1.00 \\
\hline $1971-80$ & 388 & $1.22(1.04$ to 1.42$)$ & 120 & $1.14(0.88$ to 1.47$)$ \\
\hline $1981-90$ & 322 & $1.47(1.25$ to 1.73$)$ & 68 & $1.22(0.89$ to 1.67$)$ \\
\hline $1991-2000$ & 156 & $1.29(1.05$ to 1.57$)$ & 34 & 1.39 (0.92 to 2.08$)$ \\
\hline 2001-08 & 62 & $1.94(1.45$ to 2.59$)$ & 5 & 1.54 (0.61 to 3.88$)$ \\
\hline \multicolumn{5}{|l|}{ P for trend ${ }^{*}$} \\
\hline Age at treatment & $<0.001$ & - & $<0.001$ & - \\
\hline Follow-up duration & $<0.001$ & - & $<0.001$ & - \\
\hline Treatment period & $<0.001$ & - & 0.0646 & - \\
\hline
\end{tabular}

Excess relative risk calculated as ratio of standardised incidence ratios and standardised mortality ratios, respectively. Estimates are mutually adjusted for included variables.

${ }^{*} \mathrm{P}$ values for trends across strata. 
Table 4| Excess relative risk (95\% Cl) of developing invasive cervical or vaginal cancer among women with previous CIN3 diagnosis, stratified for two levels of age at treatment for CIN3, controlling for follow-up duration and treatment period of CIN3

\begin{tabular}{lcc}
$\begin{array}{l}\text { Parameter } \\
\text { Attained age (years) }\end{array}$ & Age at treatment $<\mathbf{4 0}$ years & Age at treatment $\geq \mathbf{4 0}$ years \\
\hline$\leq 29$ & $1.16(0.80$ to 1.69$)$ & - \\
\hline $30-39$ & 1.00 (reference) & - \\
\hline $40-49$ & $1.30(1.05$ to 1.60$)$ & 1.00 (reference) \\
\hline $50-59$ & $1.60(1.10$ to 2.32$)$ & $1.50(1.11$ to 2.03$)$ \\
\hline $60-69$ & $1.86(1.07$ to 3.23$)$ & $2.90(2.12$ to 3.96$)$ \\
\hline $70-79$ & $1.78(0.81$ to 3.92$)$ & $5.48(3.95$ to 7.59$)$ \\
\hline$\geq 80$ & $4.16(0.92$ to 18.83$)$ & $8.14(5.57$ to 11.88$)$ \\
\hline
\end{tabular}

Excess relative risk calculated as the ratio of standardised incidence ratios. 


\section{Figures}

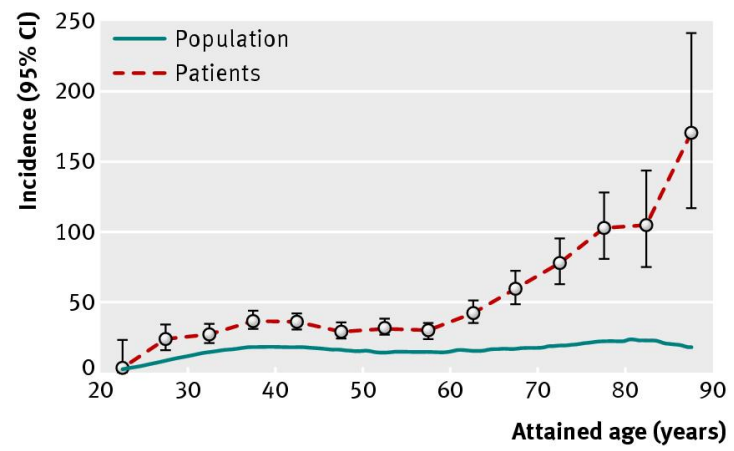

Fig 1 Incidence of cervical or vaginal cancer per 100000 person years as a function of attained age. Patients=women diagnosed with CIN3; population=general Swedish female population

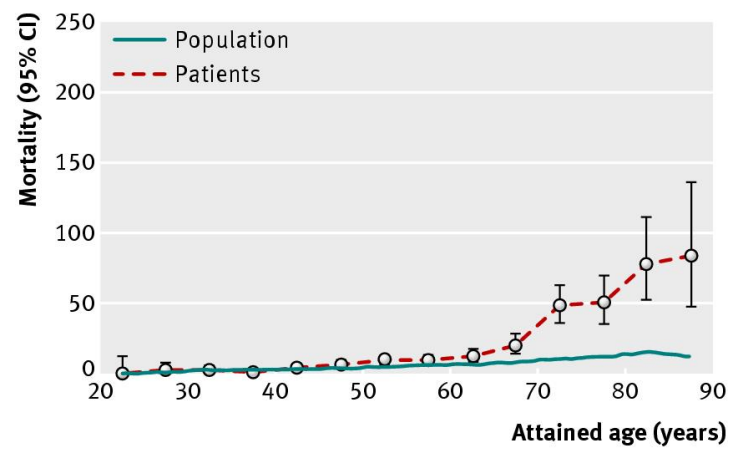

Fig 2 Cause specific mortality from cervical or vaginal cancer per 100000 person years as a function of attained age. Patients=women diagnosed with CIN3; population=general Swedish female population 